\title{
Una amistad epistolar: Ricardo Palma y Vicente Riva Palacio
}

\author{
Leticia Algaba \\ UAM-AZCA POTZALCO
}

$\mathrm{D}$

e 1884 a 1892 discurriría un in. tercambio epistolar amistoso entre dos intelectuales latinoamericanos, Vicente Riva Palacio y Ricardo Palma; sus cartas son una fuente valiosa para la comprensión de la obra literaria e historiográfica de los protagonistas, mexicano el primero y peruano el segundo, quienes empezarian a cartearse sin conocerse. Esa correspondencia fue iniciada por Palma en noviembre de 1884 y se extendería hasta julio de 1892, año en que viajó a Madrid como representante de su país a la conmemoración del IV Centenario del Descubrimiento de América. Ahí conocería personalmente a Riva Palacio, mismo que, desde 1886 , fungía como ministro plenipotenciario de México ante los reinos de España y Portugal y que era miembro entonces del
Comité Organizador de dicha conmemoración.

Mi primer contacto con la correspondencia ocurrió cuando, en 1986, trabajé en el Archivo de Vicente Riva Palacio atesorado en The Benson Latin American Collection de la Universidad de Texas en Austin (también ahora en el Archivo General de la Nación). En él leí las 36 cartas de Palma a Riva Pala. cio, y poco después, encontré un Epistolario de Ricardo Palma que reproducía aquellas mismas cartas. Comencé a indagar en Lima, epistolarmente, sobre las respuestas del mexicano al peruano. Y no fue sino hasta principios del año pasado cuando, al fin, el periodista peruano Ángel Páez me proporcionó copias de solamente cinco cartas de Riva Palacio a Palma que aparecen en el tomo II de su Epistola- 
rio $^{1}$ desconocido por mí, al menos, e inencontrable en México. He continuado la búsqueda de más de estas cartas en la Casa-Museo Palma de Lima, hasta ahora, sin ningún éxito. Dado el dificil acceso a los libros peruanos en México, consideré que las cartas de Palma y las correspondientes de Riva Palacio merecían difusión, de ahí que me haya interesado en que se incluyeran en el presente número de Secuencia.

Tanto en Ricardo Palma como en Vicente Riva Palacio es fácil reconocer su vocación literaria inmersa en el propósito historiográfico. En uno y otro es posible apreciar también una necesidad de comprender el pasado colonial. Tales paralelismos remiten necesariamente a una actitud corriente en la Hispanoamé. rica del siglo XIX Y, por ende, a una escritura literaria plenamente romántica.

Las similitudes entre el peruano y el mexicano discurren en la discrepancia de su vida personal. Casi coetáneos, Riva Palacio nació en la ciudad de México en 1832, vivió 64 años y murió en Madrid en 1896 , tras un breve pero fulminante padecimiento físico. Palma nació en 1833 en Lima y murió en la capital peruana en 1919, en una implacable victoria sobre los innumerables achaques de salud de que da cuen-

1 Ricardo Palma, Epistolario, 1949. Aparecen cartas de Paima a los siguientes escritores mexicanos: Victoriano Agüeros, Ireneo Paz, Francisco Sosa, Juan de Dios Peza y Luis González Obregón. Y de otros mexicanos a Palma: Guillermo Prieto, Joaquín García Icazbalceta, José María Vigil y A mado Nervo. Las cartas contienen tópicos de gran interés para la historia literaria del siglo xix de México y el Perú. El punto de partida es, casi siempre, el propósito de Palma por solicitar obras mexicanas para la Biblioteca del Perú. ta a su amigo Riva Palacio desde la primera hasta la última carta.

Igualmente distintas son las experiencias políticas de los dos escritores, atribuibles naturalmente a condiciones sociales distintas, pero, a mi parecer, más bien a actitudes vitales, pues ambos fueron liberales y ejercieron la filiación partidaria intensamente. Por los años en que comienza su correspondencia, Palma participaba con entusiasmo en las lides políticas. En 1866, intervino activamente en la guerra entre España y Perú, a la que siguió la revolución que llevó al poder a José Balta, de quien el escritor fue secretario particular. Tres años más tarde, en 1869, Palma ocupó un lugar en el Senado como representante de la provincia de Loreto, y poco después, se retiró para siempre del escenario político. La desilusión del que. hacer político no llegaría a conocer una tregua; Palma se mantuvo sordo a propuestas tan sugerentes como la vuelta al Senado o la invitación a representar a su país en el Secretariado de la Legación en Madrid. En 1888 le decía a Riva Palacio "ya no soy hom. bre para las luchas de partido", y le expresaba su deseo de que "lo dejaran tranquilo entre la polilla y los pergaminos", 2 y era porque, en 1884 , había iniciado la meritoria labor de refundar la Biblioteca Nacional del Perú; ahí iba a permanecer treinta años, como prueba de una pasión bibliográfica que convirtió a la Biblioteca en una de las más ricas de la América Hispana. Aquella pasión tuvo como único y excelente rival la escritura de

2 Carta de 6 de junio de 1888. 
sus Tradiciones, género que Palma lleva al paradigma en la literatura hispanoamericana.

La biografia de Riva Palacio ${ }^{3}$ nos impide pensar en una deserción del quehacer político por su parte, y desde luego, las circunstancias favorecieron su innegable vocación política. Si verificamos treguas que más bien confirman los vaivenes y los tonos, a veces muy subidos, en las polémicas partidarias o, inclusive, entre los propios correligionarios, Riva Palacio fue siempre combativo. Una de estas treguas fue, por ejemplo, su encarcelamiento por su posición antagónica en la Cámara de Diputados a propósito de la llamada "cuestión del níquel", en 1883, y que dio pie a una tarea pendiente: la composición del capítulo sobre el virreinato para la magna obra México a tràvés de los siglos, escrita bajo su dirección.

Acaso la larga estancia de Riva Palacio en Madrid como ministro plenipotenciario de México (1886-1896) constituya la verdadera tregua al quehacer político. O quizá, se trate más bien de un exilio fraguado por sus diferencias con el presidente Porfirio Díaz, luego de su renuncia al cargo de ministro de Fomento. La década en Madrid rindió frutos al diplomático y, de modo muy significativo, al escritor. Poco antes de su muerte preparó la edición de Los cuentos del general, una colección de textos que ya habían sido publicados en periódicos, y cuya factura y oficio delatan a un narrador muy alejado de la

${ }^{3}$ A Clementina Díaz y de Ovando debemos la primera (aunque no en el tiempo) biografía exhaustiva de Riva Palacio. Más recientemente, José Ortiz Monasterio ofrece magníficas semblanzas del escritor. novela histórica; sin duda, la distancia de México surtió efectos en el terreno literario.

Este nuevo camino literario de Riva Palacio muestra, de nuevo, una actitud distinta a la de Palma, quien, como señalé, dedicó a sus Tradiciones casi toda su vida y como él mismo diría al primero, no era fácil desprenderse del interés por el pasado:

..tengo para mí, ha de interesarme -se refiere a México a través de los siglosinfinito, por lo muy aficionado que soy a lo que se relaciona con la época del coloniaje que, a pesar de los pesares, tiene mucho de romancesca y de poética. Nuestro presente, amigo mío, es de un prosaísmo abrumador. 4

Las diferencias en las vidas de los dos escritores no empañan las simpatías. La correspondencia Palma-Riva Palacio comprueba a cada línea el ne. xo definitivo de la amistad: el ferviente deseo por novelar la historia colonial. Riva Palacio encontró campo fértil en los archivos de la Inquisición para la escritura de sus siete novelas, pero también escribiría Tradiciones, Episo. dios y Leyendas. Palma dedicó casi toda su vida a las Tradiciones; escribiría más de quinientas entre 1874 y 1910 basadas también en documentos que celosamente guardaba en "su hogar", la Biblioteca Nacional. En 1879, el peruano intentó escribir una novela histórica, bajo el título de Los marañones, inspirada en la aventura de Lope de Aguirre, sin embargo quedó inacabada por la destrucción que provocó el incendio de la casa y de la biblioteca

${ }^{4}$ Carta de 20 de noviembre de 1885. 
del escritor en Miraflores. Palma no volvió a frecuentar el género.

Como señalé más arriba, Palma escribió más de quinientas tradiciones. Las historias de la literatura hispanoamericana coinciden en atribuirle la invención del género, sucedáneo en parte de los cuadros de costumbres al estilo del español Mesonero y que se escribieron a lo largo del siglo xIX -en México, Guillermo Prieto es un conspicuo cultivador. Sus tradiciones se emparentan también con las leyendas, por cuanto que tiene narraciones de hechos inverosímiles, muy al estilo romántico y en los que subyace la influencia del novelista Walter Scott.

A mediados de la década de 1860 , Palma comenzó a escribir tradiciones que ya apuntaban las características que se mantendrian: anécdota centra. da en algún episodio histórico nacional, salpicada de humor e ironía y alejada de idealizaciones de corte romántico. Aunque las Tradiciones de Palma abarcan desde la época de los incas hasta el siglo XIX, en su mayoría transcurren en el esplendor del virreinato y se ubican en Lima. Se detienen amorosamente en hechos de importancia menor, no en grandes sucesos, y se trata muchas veces de escándalos como crímenes o amores ilícitos. Los personajes y los sucesos son reales pero las historias se desarrollan y culminan en la ficción. La lectura de las tradiciones pone de relieve una visión del pasado colonial teñida de ambivalencia: afecto a la herencia de los antepasados al lado de una mirada crítica; ironía y burla junto a la añoranza. ${ }^{5}$ En

5 Véase Higgins, "Palma", 1983. muchos sentidos, las Tradiciones de Palma constituyen una rica fuente para comprender el espíritu de un liberal hispanoamericano del siglo XIX. ${ }^{6}$

El cultivo de la tradición en Riva Palacio no es de gran cuantía; ya sabemos que ésta se manifiesta en sus novelas. Sin embargo, escribió episodios históricos y leyendas, con un propósito semejante al de Palma. Al alimón con Juan de Dios Peza, publicó en 1885 Tradiciones y leyendas mexicanas, volumen que contiene dieciséis textos, todos en verso de diversa métrica y organizados en estrofas cuyo número de versos obedece al hilo conductor del relato. ${ }^{7}$

Los paralelismos con las Tradiciones de Palma son frecuentes. En los textos dedicados a las calles de la ciudad de México, sobresalen los in. gredientes legendarios, esto es, los hechos sobrenaturales, pero también los sucesos infractores de la moral, como son los amoríos o los amores desventurados, elementos que, por otra parte, contribuyen al trazo de personajes románticos. No dejan los autores de indicar, de vez en cuando, sus fuentes históricas, en ese guiño usual del novelista histórico que advierte al lector sobre la veracidad de su relato, desde luego alterada por el ropaje ficticio. Las leyendas y tradiciones de Riva Palacio y Juan de Dios Peza responden, como ya he reiterado, a una escritura literaria propia del

6 Véase George Umphrey y Carlos García, "Introducción" a Palma, Flor, 1943.

${ }^{7}$ Mis juicios son un tanto preliminares ya que actualmente trabajo en un estudio literario de la narrativa de Riva Palacio y, aunque escritas en verso, incluyo las tradiciones y leyendas. 
siglo XIX hispanoamericano; en este sentido no parece pertinente indagar la influencia de Palma en Riva Palacio. Si bien es cierto que Palma consagra el género en la segunda mitad del siglo pasado, en México se escribian desde antes textos cercanos a éste. El mejor testimonio al respecto nos lo ofrece el propio Palma en una carta a Riva Palacio:

Lima y México se parecen como dos gotas de agua en punto a consejas populares. Nuestro "Zelenque" es el don Juan Manuel de ustedes. "La mujer herrada" es leyenda también de mi tierra. "La cita en la catedral" (precisamente versificada) nos es familiar. El barquichuelo de "La mulata de Córdoba" es el mismo en que se embarcó nuestra Inés la voladora para burlarse de un inquisidor...8

Las cartas que aparecen en seguida son apenas una sugerente muestra de una relación intelectual que descubre una etapa de la literatura hispanoamericana, con afinidades literarias entre Perú y México y, sobre todo, la escritura de dos hombres que imbricaron la literatura y la historia en obras que aún ahora, casi al final de nuestro siglo, son del agrado de los lectores.

\section{Carta 1}

Lima, setiembre 7 de 1885.

Sr. Gral. don Vicente Riva Palacio. México.

\section{Querídisimo amigo:}

A noche recibí sus amables cartas de 27 y 29 de julio que contesto a vuelapluma por el vapor que zarpará hoy del Callao. A la vez recibí carta de Frank, avisándome que el amigo Santacilia (a quien ruego a usted se digne saludar en mi nombre) le había entregado un cajón de libros, que supongo son los que Ud. se digna remitirme. Hoy envié a uno de mis empleados a la casa Frank y supe que, en efecto, el cajón se encuentra ya en la Aduana. Por consiguiente, en dos o tres días más, habrá sido despachado y estará ya en mi poder. No sé cómo agradecer a Ud. sus exquisitas finezas para conmigo y para con la Biblioteca de mi patria.

\footnotetext{
${ }^{8}$ Carta del 14 de mayo de 1886. Contiene una reseña sobre las Tradiciones y Leyendas que Riva Palacio le había enviado.
} 
Ciertamente que al contribuir Ud. con la eficacia que lo ha hecho, a que sean conocidos en el Perú los hombres de letras de México, llena un positivo deber patriótico y de americanismo. Así ha servido Ud. a su patria más eficazmente que todos aquellos que piensan servir ocupándose de su país sólo en el interior y no preocupándose del nombre de su patria en el exterior. El patriotismo de aquéllos tiene mucho de personal y de egoísta. No es patriotismo de buena ley.

Estimo su benévolo juicio sobre mis Verbos y gerundios. Estaba en la luna de miel y mi Cristina me obligó a publicar el librejo. Tengo muchas coplas que no sé si más tarde coleccionaré en un libro. Pásame ahora, mi querido don Vicente, que tengo en más estima mi prosa que mis versos. Amo mis Tradiciones; y apenas si tengo cariño paternal por mis renglones rimados.

Sin embargo de vivir atareadísimo en mis labores bibliotecarias, no pasa mes sin que escriba algún articulejo histórico o tradicional para uno de los diarios de Lima. Además me ocupo actualmente en hacer las publicaciones de las obras de un poeta que murió hace 15 años, y que, a mi juicio, fue un gran poeta cómico. El libro acabará de imprimirse en

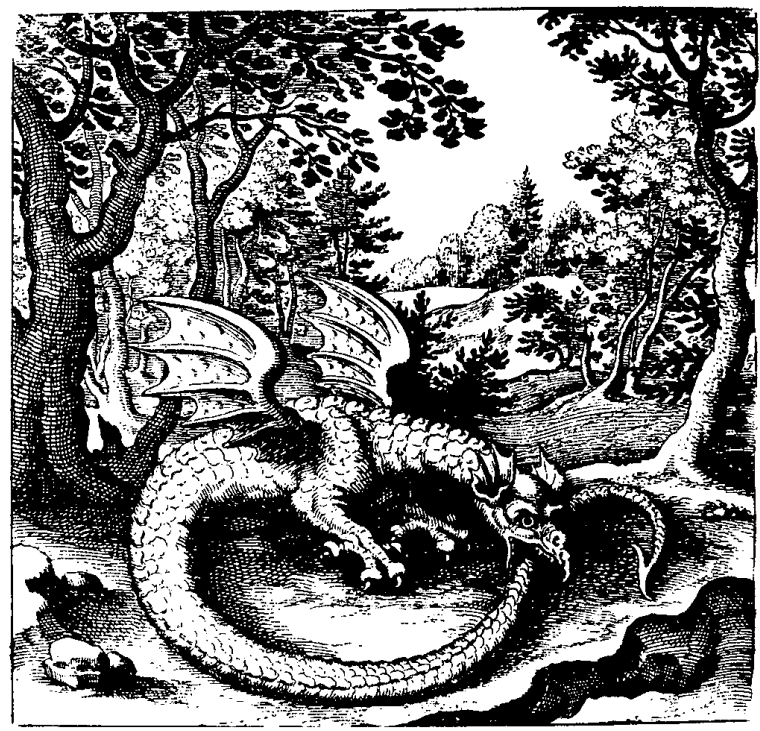


noviembre. Ya enviaré a Ud. un ejemplar de las obras de don Manuel Segura.

Ud. sí es lo que se llama un escritor laborioso. Pruébanmelo sus lindísimas Páginas en verso, de cuyo librito he leído anoche una docena de composiciones. Es Ud. un poeta galano e inspirado; pero, perdóneme la franqueza, prefiero en Ud., el prosador al poeta. Su libro Los ceros me cautivó. No dudo que Martín Garatuza, libro del que mucho he oído hablar, y ventajosamente, fortificará mi predilección por el prosista.

Tengo ya las poesías de Acuña. Me faltan las de Guillermo Prieto, Mateos y Peza.

¿Tiene Ud. facilidad para conseguir un libro -el libro rojo, verde o azul-en fin, es un color que no sé a punto fijo cuál sea, del cual me habló hace pocos días el ministro de España con gran elogio, aunque sin recordar el nombre del autor? Es libro mexicano y trata de tradiciones y leyendas aztecas.

Ya escribiré a Ud. con más extensión por el otro correo, después de haber pasado revista a los libros. Entre tanto le estrecha la mano muy cordialmente su amigo y compañero.

Ricardo Palma

\section{Carta 2}

México, octubre 5 de 1885

Sr. don Ricardo Palma.

Querido amigo:

Ayer recibí su grata, fecha 7 del pasado, y me causó gran satisfacción la noticia de que han llegado a poder de Ud. los libros que le envié por conducto del señor...

Debo decir que ignoro el motivo de haber ese señor dicho que Santacilia le había entregado el cajón, pues yo se lo remití directamente con un dependiente mío, pues a Santacilia hace más de cinco años que no lo veo, viviendo en la misma ciudad y siendo amigos. 
Soy afortunado con Ud. pues los libros que desea ver resulta que son míos, lo cual me complace, aunque me temo que lleve al leerlos un gran desencanto. Quiere Ud. el Martín Garatuza, y le tiene; quiere el Libro rojo, y se lo envié ya en el cajoncito. Ni ud. ni yo tenemos que quejarnos de la suerte.

Veré de remitirle las poesías que desea, y quizá muy pronto también, unas tradiciones mexicanas en verso que me están imprimiendo en Barcelona, aunque por venir en entregas, no será esto tan pronto como yo desearía.

¿Ya le llegó a Ud. de España, la Historia de México a través de los siglos que estamos publicando y que me dijo Ud. que había encargado a su corresponsal? Yo ya terminé de escribir el segundo tomo que es la historia de la dominación española, y fue la parte de que me hice cargo.

Diga Ud. a su corresponsal que, al enviarle la obra, no le falten los cromos, regalo de cada tomo, que son cuadros grandes y buenos.

Ahora que acabé la historia, no sé qué escribir, vacilo entre mis memorias y una historia del pueblo, es decir de la raza mexicana actual -sin personajes, sólo considerando su formación, evoluciones y desenvolvimiento, bajo el aspecto fisiológico, antropológico y sociológico, este libro presentará grandes dificultades y será, si lo escribo, el único en su especie. Para que se forme idea de mi plan, vea si ya tiene la obra de México el capítulo del libro 2 que es una muestra del estudio que me propongo. En cuanto a mis memorias, tienen de dificil que, como yo no sé ni mentir, ni adular, será necesario entrar en campaña con muchos; pero pueden ser divertidas e interesantes porque en México, y supongo que habrá sucedido lo mismo en el Perú, en pocos años han cambiado enteramente las costumbres hasta el extremo de olvidarse las que había hace treinta años. Además, como yo sostuve la guerra tantos años, viviendo como un perro rabioso y perseguido en las montañas vírgenes de la zona tórrida, y luego he visto la guerra franco-prusiana, y el sitio de París, y la Comuna, y la revolución de España; y vi desde mi balcón en Madrid asesinar a Prim, y otras lindezas por el estilo, que me han hecho tener un elevado concepto de la humanidad, que se cree civilizada, cuando es peor que los tigres de nuestras selvas, y que los caimanes de nuestros ríos, supongo que serán mis memorias, divertidas, si bien no muy morales en el sentido de lo que en el mundo se llama justicia.

En fin, ya le diré a Ud. lo que escriba y le enviaré lo que haga para que se divierta un rato.

Tengo por ahí un tomo de comedias y dramas que imprimí, pero se 
agotó a tal grado la edición, que no consigo un ejemplar; yo de lo mío nada guardo, y el único que hay en casa lo tiene Josefina, mi mujer, y primero se deja sacar un ojo. Buscaré y le enviaré uno.

Adiós, amigo, tome Ud. mi ejemplo para escribir, vea que no le pongo recetas de médico en cuatro letras y le escribo hasta mis proyectos. Que sea muy feliz.

V. Riva Palacio

\section{Carta 3}

Lima, mayo 14 de 1885

Sr. Gral. don Vicente Riva Palacio.

México.

Queridisimo amigo:

Gratísimos ratos me ha proporcionado la lectura de sus Tradiciones $y$ leyendas en verso. Es Ud. uno de los poquísimos poetas esencialmente americanos, que conozco en nuestro continente. La musa de Ud. no es de esas plañideras convencionales y amaneradas que tanto abundan en la América Latina y que no son sino imitadoras de esa poesía personal propia del mundo viejo y de sociedades ya caducas. Poesía sin propósito histórico o social es poesía de oropel. Esos poetas morirán con su siglo.

Junto con el de Ud. recibí otro libro también de la índole que yo estimo, El romancero de Guillermo Prieto, mi viejo amigo. Le contesto hoy su carta y lo felicito.

Con Lavalle me veo casi diariamente. $O$ él viene a la Biblioteca o yo voy por la noche a su casa a charlar un par de horas. Le leí el acápite pertinente de la carta de Ud. y me encarga decirle que le escribirá próximamente remitiéndole un ejemplar de su "Doctor Valdés" y otro de su "Marianita Belzunce", dos monografías que, actualmente, tiene en prensa.

Hemos tenido un certamen literario para solemnizar el centenario de Santa Rosa. A fortunadamente, pude evadirme de pertenecer al jurado. 
Resultó premiada una silva, venida de España, escrita por un señor Valladares Alcalde. La leerá Ud. en el Ateneo y verá Ud. que no es gran cosa. El único premio que yo habría acordado, tutta conciencia literaria habría sido al trabajo, en prosa, de Zegarra, un distinguido joven peruano. Es un estudio bibliográfico bastante erudito y que revela gusto y laboriosidad.

En el próximo número de la Revista social aparecerá "Bigotes", leyenda con cuya dedicatoria me ha honrado Ud. Por el vapor entrante le remitiré el número en que se publique.

Clorinda Matto me encarga dar a Ud. las gracias por el galante juicio que hace de sus Tradiciones cuzqueñas, en el acápite de carta que me permití leerle.

Volviendo a su tomo de Tradiciones y leyendas mexicanas diré a Ud. que Lima y México se parecen como dos gotas de agua en punto a consejas populares. Nuestro "Zelenque" es el Sr. don Juan Manuel de ustedes. "La mujer herrada" es leyenda también de mi tierra. "La cita en la catedral" (preciosamente versificada) nos es familiar. El barquichuelo de la "Mulata de Córdova" es el mismo en que se embarcó nuestra Inés la voladora para burlarse de un inquisidor. Como ejecución me han agradado infinito "La calle de Olmedo" en que las décimas son fáciles y frescas. Las quintillas de "La quemada" son arroyuelo entre flores. Las redondillas del "Puente del clérigo" están escritas por pluma de maestro; y en otras leyendas el romance está manejado con envidiable soltura y naturalidad. Se conoce que por error de imprenta en el romance de don Juan Manuel el verso -y "En cuenta Dios se lo tenga" - que debió ser "Dios se lo tome" Así me he permitido corregirlo en mi ejemplar.

Gracias mil por la promesa que me hace de un nuevo contingente para la Biblioteca. El 3 del entrante tendremos presidente constitucional. Es muy probable que yo renuncie mi puesto de bibliotecario o que me lo hagan renunciar; pues los hombres que van a ser gobierno son de comisura política diversa a la mía. Ya avisaré a Ud. lo que decida por el vapor próximo. Y pongo punto que el papel y el tiempo vienen estrechos a su àmigo.

Ricardo Palma 


\section{Carta 4}

México, junio 22 de 1886.

Sr. don Ricardo Palma.

Lima.

Mi querido amigo:

Mucho me alegro de que le hayan agradado tanto las leyendas que le remití; ya Ud. sabe por experiencia que los hombres de letras tenemos esas alegrías infantiles cuando nuestras producciones son del agrado de nuestros amigos, y en mi carácter, poca huella dejan el político y el soldado, y mucho estampa su sello el escritor con sus ilusiones y su exagerada susceptibilidad.

Como indiqué a Ud. en una anterior el gobierno me ha nombrado enviado extraordinario y ministro plenipotenciario para las cortes de España y Portugal. Ya sobre esto le escribí largamente; me resta sólo decirle que es casi seguro que cuando Ud. reciba esta carta estaré lejos de México. He determinado salir en los primeros días del mes que entra, tomando el ferrocarril del norte que me lleva de México a Nueva York y embarcándome de allí para Liverpool.

Mientras fijo mi residencia en Madrid, si Ud. quiere escribirle a su amigo, sobrecarte sus apreciables misivas a don Manuel Payno, París 37, Avenue Friedlan, y llegue antes o después que yo, estará segura.

Antes de irme cuidaré de enviar los libros para la Biblioteca por conducto de Sosa.

Mucho me apena el temorde que por el cambio de gobiemovaya Ud. adejar viudaa su querida Biblioteca, que tantos afanes le ha costado. Los hombrescomo Ud. deben estar fuera de la perniciosa influencia de las tempestades políticas.

No deje de escribirme lo que ocurra sobre esto.

Le envío esas hojas que contienen un fragmento de otra leyenda.

Procuraré escribirle la víspera de mi salida y termino por ahora repitiéndome su amigo que mucho le quiere.

V. Riva Palacio 


\section{Carta 5}

Lima, diciembre 26 de 1886.

Sr. Gral. don Vicente Riva Palacio.

Madrid.

Querido amigo:

Al acusarle recibo de su afectuosa del 1 de noviembre, empiezo por desearle salud y las felicidades a ella consiguientes y que estimo como secundarias, en el año que va a comenzar.

Me extraña que en París no le hayan entregado una mía y un paquetito con folletos que le remití, conforme a sus indicaciones, rotulado al señor Payno.

Hace un mes escribí a Ud. a Madrid acompañándole, en un paquete certificado, el nuevo libro de Clorinda. A la fecha lo supongo en su poder. Hay, en ese libro, un buen artículo con dedicatoria a Ud. Clorinda se encuentra ahora en Arequipa, y regresará, probablemente, dentro de cuatro meses.

Muy bueno me parece el pensamiento de Ud. de consagrar sus ratos de descanso oficial a escribir la historia de México colonial.

He leído ya todo el segundo volumen de México a través de los siglos, y mandado copiar para reproducirlos en el Ateneo (publicación literaria quincenal de Lima) las páginas que consagra Ud. a la "Monja-alférez" y a "Don Guillén de Lampart". Son artículos que tienen significación histórica para el Perú.

Habiendo encontrado entre los manuscritos de la Biblioteca de Lima uno de Gregorio López, titulado "El Apocalipsis", he escrito en el Ateneo un artículo, utilizando para su confección un librejo publicado en Madrid cuando Felipe IV se ocupaba de la canonización de aquel misterioso personaje, $y$ las noticias que Ud. consigna. Me ha salido un bonito artículo.

¿Podría comprobarse que Juan de Rada, el jefe de la conjuración contra Pizarro fue hecho conde palatino por el papa? Tengo mis motivos para dudarlo.

Ya están impresos los cinco primeros pliegos, de a 16 paginitas, de mi compilación de versos. El libro tendrá cerca de 500 páginas y no estará 
terminado hasta marzo. De los primeros ejemplares que me entreguen remitiré a Ud. el que le corresponde. Poco amor tengo a mis renglones rimados; pero, como creo habérselo dicho antes, lo publico como un saldo de cuentas con mi siglo.

En mi anterior participé a Ud. que la cuestión jesuita se había desenlazado satisfactoriamente. Aunque el presidente general Cáceres los patrocinaba y hacía fuerza de vela para que el Congreso se clausurase sin ocuparse del asunto, nosotros, los liberales, manejamos las cosas del tal modo, que conseguimos que en la penúltima sesión del Congreso se diese la ley. Aunque el ejecutivo se ha negado a ponerle el cúmplase y promulgarla, los jesuitas, temerosos de que hiciéramos con ellos una Saint Barthelemy, se apresuraron a ir, poco a poco, abandonando el país. De 23 que formaban la corporación, hoy sólo se encuentran en Lima los tres más caracterizados, con el pretexto de cobrar y pagar deudas; pero aun éstos se irán en el próximo enero. ¿Quiera Dios librarnos para siempre de esa plaga!

Conocí personalmente al comerciante español don Antonio Ortiz, que murió hace más de quince años. Era casado, y la viuda, que era una de las más lindas mujeres de mi tierra, vive aún. Tuvo cuatro hijas que heredaron la belleza de la madre, y creo que dos hijos. Una de las hijas casó con el comandante Thompson que mandaba un buque de guerra, y que pereció en un combate naval contra un buquecillo peruano, en 1880. Ortiz dejó una fortuna de un cuarto de millón, poco más o menos; pero entiendo que esa fortuna se ha evaporado. La viuda y las hijas gastaban excesivo lujo, y hoy viven modestamente. Fui amigo de ellas y las visité hasta hace once años, en que la vida de matrimonio me obligó a retraerme.

A mi amigo Tamayo y Baus le he encargado que le haga a Ud. una visita en mi nombre.

Es muy de Ud. amigo afmo.

Ricardo Palma 


\section{Carta 6}

Madrid, 4 de febrero de 1887.

Señor don Ricardo Palma.

Lima.

Mi querido amigo:

Recibí su carta fechada el 26 de diciembre, que como todas las suyas viene llena de cosas gratas para mí.

Aquí en la Academia en los días de sesión y en algunas otras partes veo a Tamayo y Baus y hablamos de Ud. Sé que personalmente, como a mí, no le conoce Ud., es un hombre de un corazón muy noble, de una inteligencia muy clara, muy amable y dulce en su trato; merece ser amigo de Ud. como Ud. de él. A mí me agrada extraordinariamente.

He tenido ocasión de conocer y tratar aquí al general Iglesias que fue presidente de Uds. Y no juzgaré sus antecedentes políticos, pero me ha simpatizado mucho, lo mismo que su familia. Tiene nuestro tipo americano perfectamente caracterizado.

Le agradezco que se haya echado a cuestas el tomo $2^{\circ}$ de la Historia de México. Tengo el proyecto, como le he dicho, de hacer una obra más extensa y separada desde el descubrimiento hasta el grito de Independencia.

Hasta ahora nada he escrito en Madrid, y todo ha sido perder el tiempo en convites, bailes, recepciones, teatros y todo eso que constituye la vida de los diplomáticos, pero estoy hastiado y prometo enmendarme, y comenzar a trabajar. Tengo el proyecto de publicar también, por tomos, una biblioteca americana con documentos y manuscritos inéditos. Me sobra el material, y sólo espero arreglar con mi gobierno la parte pecuniaria. Supongo que a esta obra se suscribirán los gobiernos de América. Lo felicito por el triunfo del Partido Liberal.

Espero las obras sobre "Gregorio López" y versos. No tengo aquí datos para hablarle de "Juan de Rada"; pero yo le diré pronto lo que hay. Le doy las gracias por las noticias que me comunica de la familia Ortiz: le escribí a sus parientes. He recibido las publicaciones que me ha enviado. Le escribí a Ud. avisándoselo y acompañándole una carta para Clorinda. 
Probablemente a esta hora las habrá recibido. No deje de darme noticias suyas y no olvide cuánto le quiere su amigo.

V. Riva Palacio

\section{Carta 7}

Lima, enero 24 de 1888.

Sr. Gral. don Vicente Riva Palacio.

Querido amigo:

Al fin, por su carta de 9 de diciembre, veo que las medallitas, después de larga peregrinación, llegaron a su destino. Si hay peligro en confiar algo al correo también lo hay en fiarse de particulares como nos ha sucedido con el niño de Pepita Hijosa, que, probablemente, es un calaverilla.

El amigo Francisco Sosa cada día más galante conmigo. Acaba de favorecerme con un artículo que he hecho reproducir en el Ateneo.

García Icazbalceta me remitió su libro-Bibliografía mexicana en el siglo XVI. Es un buen trabajo. Al final trae unas apuntaciones sobre la Inquisición en México, que me han hecho sonreir; pues a Icazbalceta le parece poco que los inquisidores hubieran quemado sólo 41 prójimos.

Por lo demás yo me precio de tolerante con los conservadores. En el terreno de la idea la combato siempre que puedo; pero en el de la estimación individual, cuando directamente no me hieren, o me han dado motivo de queja, cultivo con ellos relaciones de estricta cortesía. No los trato con la llaneza e intimidad con que trato a los correligionarios como Ud. o Sosa; porque eso no es posible.

Larga conversación mantengo con los literatos colombianos, "conserveros" casi todos. Pues bien, sólo con uno, Aníbal Galindo, tengo expansiones; porque es el único de mi escuela. Con los otros, ni ellos entran en el campo de las doctrinas, ni yo, por supuesto. Cada cual siga su camino. Ni yo los he de hacer desertar de su bandera ni ellos han de pretender arrastrarme a sus filas. Por fortuna el contacto con los conservadores está muy lejos de producir contagio. No ofrece el peligro del cólera. 
Esta epidemia sigue haciendc estragos en Chile, y amenazando aparecerse en el Perú a pesar de las cuarentenas y otras medidas adoptadas por el gobierno. Que Dios nos libre de la visita de tan temible viajero.

Nuestro amigo el general Iglesias llegó a Panamá con la familia; pero allí se le intimó por el cónsul que no continuara viaje al Perú, pues sería apresado en el primer puerto a donde llegase. La señora y las niñas siguieron para Pacasmayo, puerto vecino a las haciendas de Iglesias; $y$ éste tuvo que regresarse a Nueva York. Todo miserias políticas, amigo mío. El circulillo que hoy está en el gobierno es de lo más intransigente que cabe. A mi pobre Biblioteca no le dispensan la más ligera protección, y, ¿por qué? porque cupo a Iglesias la suerte de haber iniciado la reorganización de ella. Por lo demás, personalmente, así el general Cáceres como sus ministros me colman de atenciones cada vez que tengo precisión de acercarme a ellos. Me prometen mucho en favor de la Biblioteca y... nada me cumplen. He resuelto, pues, cruzarme de brazos y que la Biblioteca siga estacionaria.

Hasta otra, mi excelente camarada.

Es muy de Ud. amigo afmo.

Ricardo Palma

\section{Carta 8}

Legación de los Estados Unidos Mexicanos en España

Madrid, 3 de marzo de 1888.

Señor don Ricardo Palma.

Lima.

Querido amigo:

He tenido una larga temporada de enfermedades y esto me ha impedido escribirle como deseaba después de haber hablado con nuestro amigo Tamayo en lo relativo al nombre de la Academia: porque habiendo leído la carta de Ud. me encargó que yo le escribiera diciéndole que lo que le 


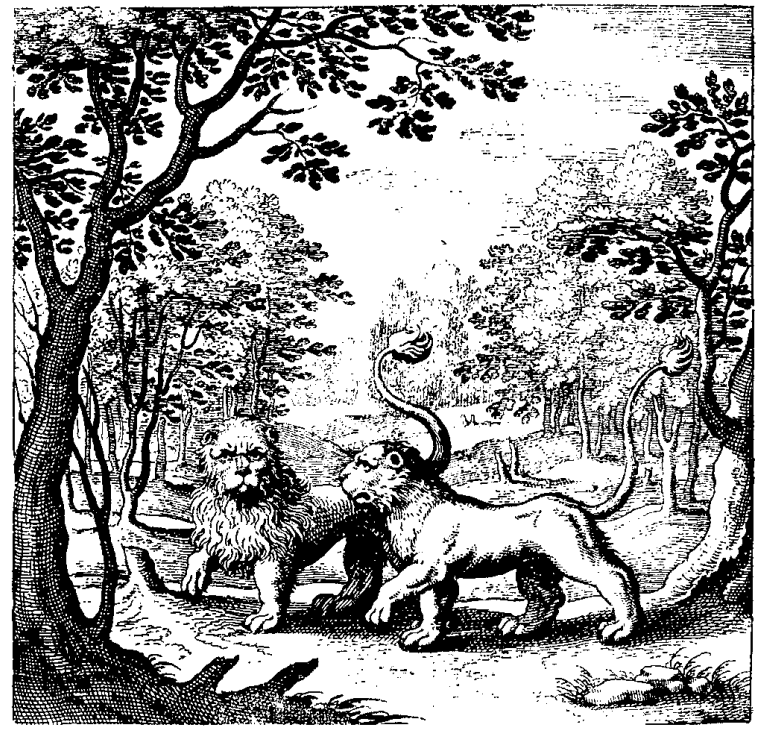

había indicado era casi una chanza, y no una cosa seria; que él también se lo escribiría a Ud. porque los americanos somos muy susceptibles. Yo pensé que más vale así.

Se está proyectando aquí establecer academias de la historia correspondientes de la de España en las naciones americanas: no me parece malo el proyecto, y hablé con el marqués de Molins encareciéndole la necesidad de no ir a entregar esa institución en México en las mismas manos a que está entregada la Academia de la Lengua, que han conseguido hacerla antipática convirtiéndola en una "cucarachera" de aduladores de Icazbalceta, de Roa Bárcena, de Segura, y de otros semejantes, que forman un grupo de reaccionarios: la mayor parte servidores del imperio y de los franceses en la criminal invasión que se hizo a México: porque yo creo, como Séneca, que no es posible ser buen orador, ni buen literato, cuando no es el hombre buen ciudadano. Los reaccionarios, los ultramontanos rabiosos, están en un periodo de excitación creyendo que las cosas del mundo pueden volver atrás. El jubileo del papa les ha sacado de juicio, y tienen por segura la reacción y la vuelta, si no a los tiempos de Felipe II, sí al menos a los del virreinato de principios de este siglo. Y sì 
los gobiernos americanos no procuran enfrenarlos, no conseguirán todo lo que intentan, pero nos darán malos días.

A pesar de mis deseos por escribir algo, todavía no emprendo nada que valga la pena. Veré qué hago; pero me falta energía para comenzar, y aquí se pierde muchísimo el tiempo.

Las noticias que tengo de México me desalientan mucho porque ha entrado alli una fiebre de toros, contagio de esta tierra, que según me escriben es tal, que sólo en la ciudad de México hay iseis plazas! ¡Diga Ud. qué se puede esperar de esto! El papel se acaba y yo me despido deseando a Ud. toda clase de felicidades.

Vicente Riva Palacio

\section{Carta 9}

Lima, abril 21 de 1888.

Sr. Gral. don Vicente Riva Palacio

Madrid.

Querido amigo:

Después de largo silencio suyo, he recibido su carta del 3 de marzo. Veó por ella, que sigue Ud. entregando al dolce far niente, lo que es de lamentar. Lleva Ud. ya casi dos años de fiestas y holganza, y ya es tiempo de que limpie el moho que ha debido crear su pluma, y vuelva a la actividad antigua.

Dentro de dos días celebraremos los académicos una fiesta religiosa -la misa del 23 de abril, aniversario de la muerte de Cervantes. Creo que nos saldrá lucida la ceremonia. Por lo menos tendremos gran concurrencia de señoras a la misa. Y donde están ellas en mayoría, todo sale bien.

¿Por qué no han nombrado correspondiente de la Academia de la Historia a José Antonio Lavalle? Pregúnteselo a Fernández Duro, que escribió un juicio sobre un trabajo histórico de Lavalle, $o$ al marqués de Molins.

Por lo que hace a organizar en Lima una correspondiente de la Acade- 
mia de la Historia, ni entro ni salgo. Los únicos correspondientes son Larrabure y yo. Molestias, y no pocas, me ocasionó mi empeño en organizar la correspondiente de la española. No quiero buscarme enojos.

Añada Ud. que hoy las dificultades serían mayores; pues el mil veces maldecido discurso del banquero Calzado ha despertado prevención contra todo lo que signifique alianza con España. Estaba ya para inaugurarse la Unión Ibero-americana cuando llegó el consabido discurso. Fue una bomba que estalló en el campo de las simpatías que los sudamericanos tenemos por España y por sus hombres. No cabe unión con quienes nos insultan tan sin razón ni pretexto, dijeron algunos de mis paisanos, y el proyecto de unión ibero-americano se desvaneció. La influencia del ministro español en Lima, Ojeda, que es muy querido y considerado en Lima, logró impedir que la prensa peruana se desbordase. No ha sucedio lo mismo en Guayaquil (Ecuador) ni en Bogotá (Colombia). Es probable que haya Ud. leído los juiciosos y patrióticos artículos editoriales del Globo, diario de Guayaquil.

Es triste que un burro con herrajes de oro como el banquero Calzado, un hombre que no ha escrito un solo libro, haya sido el sembrador de la discordia. Ese señor Calzado, de puro pedante, ha hecho un gran mal a su patria, mal que de rechazo nos hiere a los americanos que amamos a España. En Lima nos llaman a los académicos "los españolizados", mote con que nos recriminan y nos ponen como nuevos. Gracias al mal inspirado banquero, España ha perdido en Sud-A mérica mucho terreno. Aun en Chile hay riesgo de que se disuelva la Academia Correspondiente. Por fortuna en la de Lima hemos sido más tolerantes con las injurias del $\mathrm{Sr}$. Calzado.

La Academia chilena no funciona, porque a cuatro de sus miembros los ha herido infinito el discurso de aquel prójimo. Sin embargo Lastarria (el director) se afana por calmarlos. No me parece imposible que lo consiga.

Recibí últimamente carta de Sosa. En ella me anuncia el envío de su folleto antitaurófilo, que probablemente se habrá extraviado en el correo. Aquí hay una sola plaza de toros y gran afición a las corridas. Yo mismo soy muy aficionado y rara vez dejo de concurrir. Desde diciembre hasta fines de abril tenemos toros los domingos. Pero lo que, según Ud. me informa, pasa en México donde hay seis plazas, ya es peligroso y merece que se combata.

Nuestro amigo el general Iglesias no pudo desembarcar en el Perú y está en Centro América. Su esposa, la señora Concepción, llegó con las 
niñas a Cajamarca y murió hace un mes. En la misma semana murió en Lima un hermano del general. ¿Qué cosa tan mezquina es la pasión política! El gobierno se asusta (sin motivo) hasta de la sombra de Iglesias. Hasta otro día, mi querido amigo. Siempre suyo.

Ricardo Palma

\section{Carta 10}

Madrid, enero 8 de 1891.

Señor don Ricardo Palma.

Lima.

Mi querido amigo:

Muy conforme estoy, y debo estarlo, quiera o no quiera, con aquello de que,

nuestras vidas son los ríos

que van a parar al mar

que es el morir

pero no me resigno con que el verso diga

nuestras amistades son los ríos

que van a parar al mar

porque eso ni sale verso, ni es verdad. Usted me dirá, como Pardo, nuestro poeta americano, en su letrilla del ministro y del pretendiente " $y$ eso a qué viene?" y con el mismo poeta le contestaré a Ud.

Excelentísimo

Señor, a pelo, que es ya grandísimo

mi desconsuelo 
Porque hace muchos meses, hasta la cuenta he perdido, que no tengo de Ud., más noticias que las que pesco con el anzuelo de un cariñoso interés, en el manso y sosegado lago de la Real Academia de la Lengua.

Como si lo viera, sé que me va Ud. a echar la culpa a mí: yo, que no me quedo atrás, se la echo a Ud. y como dice Breton:

yo echo la culpa a los cómicos, y ellos me la echan a mí

Pero el resultado final es el mismo, sea el culpable cualquiera de los dos.

Sabrá Ud. que con motivo del Centenario de Colón, la república de las letras españolas, y el americanismo, van despertando. Y sin entrar en pormenores que serían largos y pesados, y que Ud. en los periódicos puede ver, me limitaré a hacerle un resumen en esta carta que me propongo que sea extensa, siquiera como prueba de enmienda, para que esté Ud. al tanto de cosa que nos interesa, por tratarse de nuestra común y querida patria, la América, y de la por nosotros, cultivada lengua del Conde de Cheste, porque eso de decir de Cervantes, es ya tan viejo como repetido.

Para el centenario está dispuesto, en primer lugar, que el Congreso A mericanista se reúna en Santa María de la Rábida. Que haya una exposición en Madrid de objetos americanos de la época precolombina. La Real Academia de la Lengua abre un concurso literario para premiar el mejor canto en honra de Colón y del descubrimiento de América. La misma docta corporación quiere imprimir una antología americana y española con las composiciones más escogidas de los mejores poetas, y una historia compendiada del movimiento literario de cada nación en que se habla la lengua española, encargando este trabajo a las academias correspondientes donde las haya, o a la comisión que nombre el gobierno en donde no existan las academias; y además publicar una bibliografia americana desde la conquista hasta la fecha. Finalmente Núñez de Arce con la Sociedad de Escritores y Artistas quiere convocar, para entonces, un congreso literario hispano-americano. Con que, ya ve Ud. que la gente se mueve.

Habrá llegado a su noticia que para celebrar la inauguración de la Academia Correspondiente del Perú y de México, la Real Academia de Jurisprudencia celebró una sesión solemne, que realmente estuvo muy lucida. Yo pensé mucho en Ud. figurándome que entre otras razones, por nuestra amistad tendría Ud. mucho gusto de que nuestras dos naciones hubieran ido juntas. Como no hay ministro del Perú tenía yo la ilusión de 


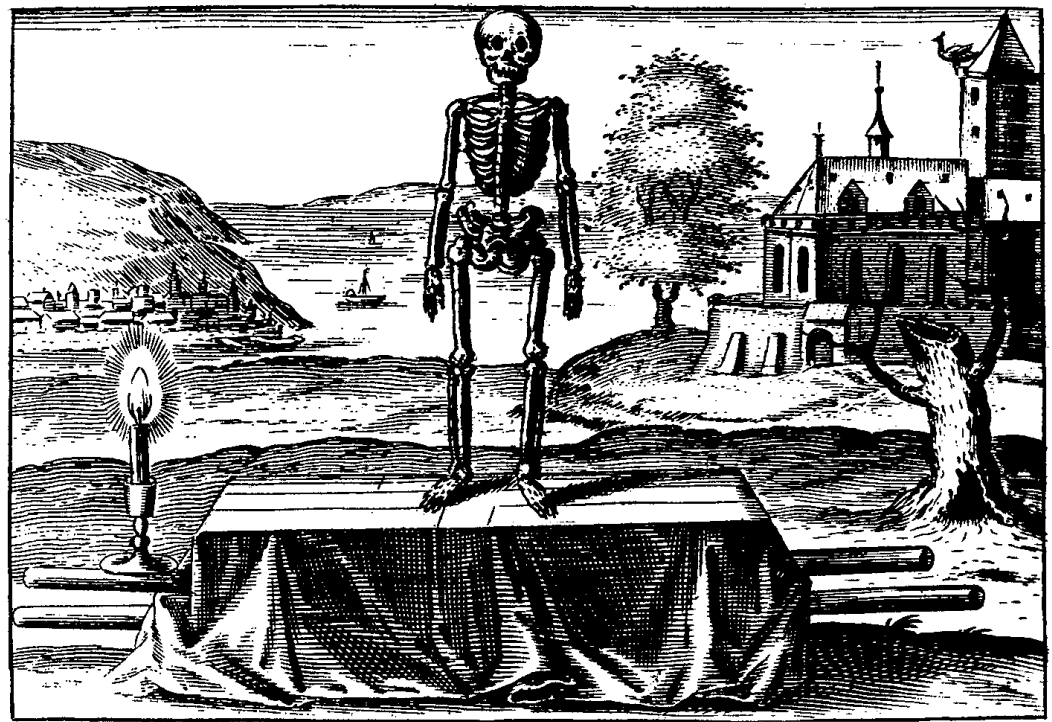

dar las gracias también en nombre del Perú, porque se prestaba mucho para hablar de nuestra fraternidad americana; pero mi gozo cayó en el pozo, porque habló el cónsul del Perú.

Vamos a otra cosa, también sin entrar en detalles.

En tiempo de la conquista de México había, en la Nueva España, un grande y poderoso reino de Michoacán, al que los conquistadores llamaron de los tarascos, cuya religión, costumbres e idioma, eran completamente distintos de los de México. Por sospechas, si es permitido darles este nombre, creo que ese reino fue poblado por una gran inmigración que salió del Perú. Así parecen indicarlo algunas prácticas religiosas, como la adoración al Sol; algunas tradiciones, como la de los cinco hermanos o compañeros que vivían en una cueva; y de una Virgen, y en fin, otras muchas, que no le pongo por vagas, pero que estudiadas pueden llegar a ser focos de luz.

Esa emigración, en su éxodo, habitó indudablemente muchos años en Venezuela; dejó allí pueblos cuyos nombres se conservan y que estudiados en el idioma tarasco dan algunos de ellos, como Caracas, muestras de relación filológica, con otros de Michoacán como Carácuaro, que significa lugar o pueblo en altura. 
Creo que con el adelanto que tenemos en los estudios de la historia y de los idiomas antiguos americanos, podría yo convencerme de si es una verdad, que esa gran parte de la población del Perú, salió de su patria caminando por las costas del Pacífico hasta fundar el reino de Michoacán en la república del norte; y de ser cierto daría una gran luz a la historia de América.

Por la parte que toca a la historia de Michoacán y a su idioma, cuento con un amigo mío muy querido, muy inteligente y muy observador que se llama Eduardo Ruiz, que escribe la historia de Michoacán y que es quien me sugirió la idea de esa emigración y me dio sus fundamentos que me parecen acertados.

A Venezuela escribo pidiendo los datos que sea posible encontrar, ya sobre tradición del hecho a que me refiero, ya sobre el idioma más antiguo de que haya noticia, ya sobre la significación de los nombres geográficos y situación de los lugares para hacer la comparación, y diré a Ud. de paso, que he hablado con el señor Martel Carrión, venezolano que ha sido gobernador de un departamento situado al sur de Venezuela, que se ha dedicado a los estudios antiguos, y me ha dicho que entre los indios de alli hay la creencia de que sus antepasados vinieron de la tierra del oro, que entenderemos nosotros por el Perú, ¿no es verdad?

Ahora para el tronco de la familia, tengo esperanzas en que Ud. me ayude. Sabe Ud. ya cuál es el fin que persigo: necesito lo que a juicio de Ud. sea mejor respecto de antigua historia o tradiciones del Perú: es decir, de lo que podríamos llamar, su libro de génesis; y en materia de idioma, qué es lo mejor que se ha escrito sobre el antiguo idioma, lo mismo que respecto de la religión del sol en aquella nación. Como Ud. sabe mucho de esto y además tiene facilidad de consultar con los sabios de su país, me prometo muy buenos datos; porque Ud. comprende que es un problema histórico, no sólo importante y curioso, sino simpático para Uds. y para nosotros; que estoy resuelto a trabajar o, cuando menos, a confeccionar todos los datos para que mi ahijado Eduardo Ruiz los desenvuelva, pues creo hacerle con esto, importante servicio a la historia de América.

La carta salió muy larga: pero me supongo que no le habrá fastidiado por que sé que Ud. es de veras amigo de éste su amigo que tanto le quiere y desea su felicidad.

Vicente Riva Palacio 


\section{Carta 11}

Lima, marzo 3 de 1891.

Sr. Gral. don Vicente Riva Palacio.

Madrid

Querídisimo amigo:

¡Que repiquen en Yauli! Al fin, después de larguísimo silencio por parte de Ud. que no mía, me llega su apreciable carta a que hoy contesto. Ya empezaba a creerme olvidado por Ud. Gracias a Dios que ello no es cierto. Tan interesante es su carta que he creído no cometer pecado de indiscreción al darle publicidad en El Nacional. Mi propósito ha sido llamar la atención sobre el tema histórico de Michoacán, tema interesantísimo, a fin de ver si otros nos ayudan con datos. En lo que yo conozco, es la primera vez que llega a mi noticia la presunción de que una tribu peruana hubiera llegado hasta Venezuela y México. Dúdolo muy mucho: pero como dudar no es negar, ha despertado Ud. mi curiosidad y voy a echarme a investigar. Ya comunicaré a Ud. el fruto de mis investigaciones. En Cronistas de Indias estoy seguro de que nada se encuentra sobre ese punto. Si algo hay será en los trabajos de misioneros y de viajeros. He hecho separar más de cuarenta volúmenes para engolfarme en ellos desde mañana. Lamento sólo que lo achacoso de mi salud no me consienta consagrar a esta labor toda la poca actividad que en mi espíritu queda. Pero, en fin, con paciencia y saliva un elefante desvirgó a una hormiga.

Vivo en constante correspondencia con nuestro viejo Guillermo Prieto y con Pancho Sosa. Éste se queja de que Ud. ya no le escribe. Supongo que le habrá enviado su bonito libro Escritores sud-americanos.

Ando en arreglos con Montaner y Simón, libreros de Barcelona, para hacer una buena edición, ilustrada, de ocho series de Tradiciones, las siete ya conocidas y una inédita. Mi ideal es un libro igual al México a través de los siglos.

He recibido por el último correo, carta de nuestro buen Tamayo y Baus. Siento infinito que se halle tan enfermo como me manifiesta. Que Dios nos lo conserve siquiera diez años más! ¿Por qué no hemos de aspirar a ver los albores del siglo XX?

Creo que las fiestas del centenario, en 1892, serán literariamente espléndidas, y que los poetas americanos contribuirán con entusiasmo a 
la solemnidad. Cinco diarios del 28 de febrero han publicado las bases del certamen poético iniciado por la Academia.

Sáqueme Ud. de una curiosidad. ¿Qué hay de nuestro compañero y amigo don Pedro Antonio de Alarcón? Unos dicen que se ha vuelto loco; otros que decepciones políticas han abatido su espíritu; cuentan no sé qué historieta doméstica; afirman que está atacado de parálisis y añaden que se ha entregado a la melancolía y que a nadie habla ni recibe. Tres cartas le he dirigido sin merecer respuesta. Es muy antiguo camarada mío y lo quiero con toda el alma. Déme Ud. noticias de él.

Habríamos visto con placer, en Lima, que en la fiesta de la Academia jurídica hubiera Ud. hablado en representación de su patria y del Perú, donde Ud. tiene gran número de apasionados y no pocos amigos entusiastas.

Nuestro amigo el general Iglesias sigue en la hacienda, no ha venido a Lima hasta ahora. Convencido estoy de su firme resolución de no meterese más en política y, sin embargo, con motivo de la abortada revolución del 3 de diciembre, se intentó ponerlo preso en Cajamarca juzgándolo comprometido en ella. Por fortuna, el gobierno retiró la orden, pues los amigos de don Miguel logramos inspirar la convicción de que no tuvo arte ni parte en el motín.

Ha ido a Europa con el carácter de ministro del Perú en Francia e Inglaterra, el ex presidente general Cáceres. Quizá dé un paseíto por España y tenga Ud. ocasión de conocerlo y tratarlo. Su figura personal acaso le parezca a Ud. más distinguida que la de Iglesias; pero es menos simpático. A mí en sus cuatro años de gobierno me trató con mucha deferencia, sin embargo de saber que fui y soy muy amigo de Iglesias. Días antes de que cesara en la presidencia casi tenemos una pelotera, aunque lo que iba a motivar no era él sino su ministro de Relaciones Exteriores el responsable. La historia fue ésta. Con motivo de inaugurarse la estatua de San Martín, leí yo unos versos en la ceremonia oficial. El ministro de Chile entabló reclamación diplomática por ellos, y nuestro ministro de Relaciones lo satisfizo declarando que el supremo gobierno había escuchado la lectura de mis versos con gran disgusto y que su publicación se había prohibido a los periódicos. Supongo que esos versos los habrá Ud. leído en el diario de Gonzalo Esteva. Posteriormente han aparecido en un folletito en Buenos Aires.

Chile anda envuelto en una atroz guerra civil, que lleva apariencia de ser muy larga. Aventurado es presentir el éxito, sin embargo de que, hasta ahora, todas las probabilidades están a favor del gobierno. La revolución sólo cuenta con Iquique, que geográficamente, no es Chile. Es como si 
se sublevara la escuadra española y no poseyendo territorio en la península se apoderara de Cuba o Puerto Rico. En el interior del departamento de Iquique está todavía en pie una fuerte división del gobierno y no sería extraño que recobrara el puerto arrojando de él a los de la revolución que son dueños del mar. Hasta hoy, como la revolución no ha tenido base de ejército, sus tropas son reclutas y andan escasas de armamentos y municiones. El gobierno está seguro de la lealtad del ejército, y se lo garantiza el antagonismo entre marinos y militares. Los revolucionarios son los ricos y todo lo que se entiende por aristocracia y gente decente. Con el gobierno están los soldados y la populachería. Dinero tiene también el gobierno pues ha echado mano a los veinte millones que tenía en arcas para el arreglo de la deuda externa. Para mí la revolución no tiene otra razón de ser que la codicia de los banqueros para adueñarse del salitre de Tarapacá, y repartirse entre ellos los negociados salitreros. Dos son las causas en que fundan la revolución: $1^{\text {a }}$ Que el presidente Balmaceda apoya a un candidato para que sea su sucesor, como si alguna vez, en Chile, hubiera subido a la presidencia otro candidato que el oficial. A eso ha debido Chile su progreso, su paz y sus victorias sobre el Perú. La otra causa es que Balmaceda (que por año y medio ha vivido en lucha con el Congreso) no convocó a las cámaras para que dictaran el presupuesto de 1891. Quien lea con imparcialidad el Manifiesto que dio Balmaceda el 1 de enero (seis días antes de que se sublevara la escuadra) no podrá menos que justificar el procedimiento del ejecutivo.

¿Cree Ud. las dos causales que los revolucionarios alegan suficientes para lanzar a un país en el escándalo y los horrores de la guerra civil?

No esconderé a Ud. que, como peruano, me gusta que los lobos se muerdan y destrocen entre ellos. Con el salitre que nos arrebataron al apoderarse del departamento de Tarapacá, se llevaron el germen de la anarquía y de corruptora riqueza. Proclamaron el derecho de conquista, y están cosechando el fruto. Chile, después de un año de revolución, necesitará un cuarto de siglo para convalecer. Desde que los chilenos se encontraron ricos con lo ajeno, perdieron el juicio, y con la revuelta han llegado al colmo de la locura.

La revolución ha llegado a revestir otro carácter terrible: el de la guerra social. Los pobres de un lado, los ricos del otro lado. Añada Ud. que el carácter chileno es feroz: la civilización no ha alcanzado todavía a destruir en el hombre chileno el salvajismo del araucano. Relativamente no hay país en que abunden más los incendiarios. Un criado o peón quiere vengarse de sus patrones e incendia la casa o la hacienda. En 
cuanto al asesinato, es universal la fama del corvo (nombre de un puñal usado por la gente del pueblo). Si la frenología es ciencia, ella confirma que no hay cráneo chileno en que la protuberancia del robo no esté desarrollada.

(Falta el final de esta carta).

\section{Carta 12}

Lima, julio 15 de 1892.

Sr. Gral. don Vicente Riva Palacio.

Madrid.

Queridísimo amigo:

Al fin voy a tener la satisfacción de dar a $U d$. un abrazo en verdad ya que tantos le he dado en espíritu. En la primera quincena de setiembre me tendrá Ud. en Madrid. Mi gobierno me ha investido con las prerrogativas de ministro residente y el cargo de delegado del Perú a los Congresos Americanista, Literario y Geográfico.

Me acompaña en el viaje mi hija Angélica, chiquilla de trece años. Comprende que va a servirme de embarazo para viajar pero, ¿qué hacer? Ella ha querido acompañarme y soy tan padrazo que he cedido.

Como pronto he de ser carta viva, pongo a ésta punto final.

Lo saluda su amigo.

Palma

RELACIÓN DE CARTAS

1. De Palma a Riva Palacio, Lima, 7 de septiembre de 1885.

2. De Riva Palacio a Palma, 5 de octubre de 1885. 
3. De Palma a Riva Palacio, 14 de mayo de 1886.

4. De Riva Palacio a Palma, 22 de junio de 1886.

5. De Palma a Riva Palacio, 26 de diciembre de 1886.

6. De Riva Palacio a Palma, 4 de febrero de 1887.

7. De Palma a Riva Palacio, 24 de enero de 1888.

8. De Riva Palacio a Palma, 3 de marzo de 1888.

9. De Palma a Riva Palacio, 21 de abril de 1888.

10. De Riva Palacio a Palma, 8 de enero de 1891.

11. De Palma a Riva Palacio, 3 de marzo de 1891.

12. De Palma a Riva Palacio, 15 de julio de 1892.

\section{BiLIOGRAFÍA}

Díaz y de Ovando, Clementina, Introducción y selección a Antología de Vicente Riva Palacio, Universidad Nacional Autónoma de México, México, 1976 (Biblioteca del Estudiante Universitario, 79).

Higgins, James, "Ricardo Palma en el desarrollo de la narrativa peruana", en Cielo abierto, Lima, enero-marzo, 1983, pp. 3-9.

Ortiz Monasterio, José, "Los dramas y novelas históricas de Vicente Riva Palacio", tesis de licenciatura, Universidad Nacional Autónoma de México, 1990, 2 vols.

—, "Las novelas históricas de Vicente Riva Palacio", Secuencia, núm. 21, septiembre-diciembre de 1991 , pp. 19.47.

Palma, Ricardo, Tràdiciones peruanas completas, Aguilar, Madrid, 1968. tica, Lima, 1949.

, Epistolario, pról. Raúl Porras Barrenechea, vol. 1, Editorial Cultura Antárca, Lima, 1949.

Epistolario, pról. Rafael Heliodoro Valle, vol. 2, Editorial Cultural Antárti-

- Flor de Tradiciones, intr., selec. y notas de George W. Umphrey y Carlos García Prada, Editorial Cultura, México, 1943.

Riva Palacio, Vicente, y Juan de Dios Peza, Tradiciones y Leyendas Mexicanas, J. Ballescá y Compañía, Editores, México, 1920. 